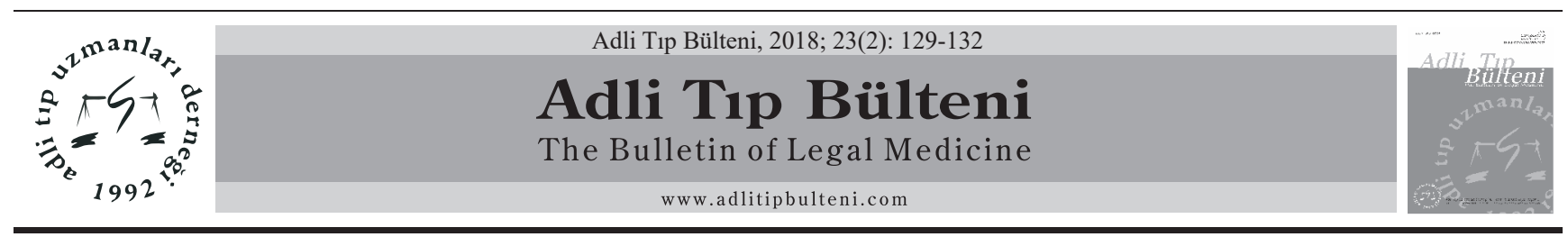

OLGU SUNUMU / CASE REPORT

doi: 10.17986/blm.2018238627

\title{
Sıra Dışı Bir Kaza ile Meydana Gelen ve Ölümle Sonuçlanan Alüminyum Fosfit Zehirlenmesi: Olgu Sunumu
}

\author{
Aluminium Phosphide Poisoning Which Occurring with An Unusual Accident and \\ Resulting in Death: Case Report
}

Hülya Karadeniz', Halil Boz², Hüseyin Çetin Ketenci ${ }^{2}$

${ }^{1}$ Karadeniz Teknik Üniversitesi, Adli Bilimler Enstitüsü, Trabzon

${ }^{2}$ Adli Tıp Kurumu, Trabzon Grup Başkanlı̆̆l, Trabzon

\section{Özet}

Alüminyum fosfit nemle teması halinde fosfin gazı oluşturan yüksek toksisiteye sahip bir insektisittir. Tarım ürünlerinde kalıntı bırakmaması ve difüzyon kapasitesinin çok yüksek olması nedeniyle uygulandığı ortamdaki tüm canlıları farklı gelişim evrelerinde öldürebilmesi nedeniyle sıkça kullanılmaktadır. Halen özgün bir antidotu bulunmayan alüminyum fosfit zehirlenmelerinde ölüm oranları alınan doza bağlı olarak \%30 ile \%100 arasında değişmektedir. Bu çalışmada; bir binanın zemin katında bulunan gıda deposunun fumigasyonu sonrasında, birinci kattaki evinde sıra dışı bir şekilde alüminyum fosfit zehirlenmesi sonucu ölen 13 yaşındaki kız olgu ele alınmıştır. Olgunun otopsi raporu, toksikoloji ve patoloji bulguları birlikte değerlendirilerek konunun literatür eşliğinde tartışılması, oral kullanımı ve inhalasyonu halinde yüksek ölüm riski taşıyan alüminyum fosfitin ülkemizde kontrolsüz satışının ve kullanımının sebep olabileceği bazı olumsuzluklarla birlikte bazı çözüm önerilerinin vurgulanması amaçlanmıştır.

Anahtar Kelimeler: Alüminyum Fosfit; Zehirlenme; Otopsi; Toksikoloji.

\begin{abstract}
Aluminium phosphide is an insecticide that shows highly toxic activity when it reacts with water or moister and becomes phosphine. Because it has high diffusion capacity, it can kill all the organisms in different growth phases in the area that it is used. However, it is used frequently due to not to find rests on plants. There is not a specific antidote for aluminium phosphide and mortality from $30 \%$ to $100 \%$ in poisoning and it is related with exposure. In this study, we present 13 years girl case who was poisoned by aluminium phosphide. He was found in his apartment which is at first floor, after fumigation of food store at the basement. We aim to evaluate by autopsy findings, chemical and histopathological findings together and to discuss with literature results. In addition, we want to discuss about solution of uncontrolled dealing and using of aluminium phosphide in our country.
\end{abstract}

Keywords:Aluminum Phosphide; Poisoning; Autopsy; Toxicology.

\section{Giriş}

Depolanmış tahılları ve ürünleri haşere ve böceklerden korumak için alüminyum fosfit kullanılmaktadır. Alüminyum fosfit; celphos, quickphos, synfume ve phosfume gibi farklı ticari preparatlar halinde İran ve Hindistan gibi ülkelerde oldukça sık kullanılmaktadır (1). Kuzey Hindistan'da genç ergenlerde özkıyım amaçlı alüminyum fosfit kullanımı sonrası ölüm olgularına sıklikla rastlanmaktadır (2). İran'da da son yıllarda özkıyım amaçlı alüminyum fosfit en sık kullanılan ajanlardan biri olarak saptanmıştır (3).

Sorumlu Yazar: Doç. Dr. Hülya Karadeniz

Karadeniz Teknik Üniversitesi, Adli Bilimler Enstitüsü, Trabzon

E-mail: gulsu@ktu.edu.tr

Geliş: 16.02.2018 Düzeltme: 16.03.2018 Kabul: 16.03.2018
En s1k rastlanan orijin intihar olup sonrasında kazalardır. Normal koşullarda katı bir bileşik olan alüminyum fosfitin cilde teması yoluyla oluşan zehirlenmeler yaygın değildir. Metal fosfitlerin üzerinde oluşan nem tabakasının meydana getirdiği fosfin gazının solunmasıyla da zehirlenmeler meydana gelmektedir. Alüminyum fosfit oral yolla alındiktan sonra midede bulunan su ve hidroklorik asitle hızlıca reaksiyona girerek toksik olan fosfin gazının oluşumuna neden olur (Şekil 1).

$$
\mathrm{AlP}+3 \mathrm{H}^{+} \rightarrow \mathrm{Al}^{3+}+\mathrm{PH}_{3}
$$

Şekil 1. Fosfin gazının oluşum reaksiyonu. 
Fosfin gazı 10-15 dakika gibi kısa bir sürede mideden emilerek kan yoluyla sistemik dolaşıma geçer. Alüminyum fosfit zehirlenmesi metabolik asidoz, aritmi, akut respiratuar distres sendromu, şoka sebep olur ve spesifik antidotu yoktur. Etki mekanizması tam olarak bilinmemesine rağmen değişik hayvanlar üzerinde yapılan deney sonuçlarına göre bilinen temel etkisi mitokondriyal sitokrom c-oksidaz enzimini inhibe etmesidir. Bu yolla hücre membranında lipit peroksidasyonu ve protein denatürasyonu meydana gelir, hücresel düzeyde oksijen kullanımı bozulur ve serbest oksijen radikalleri oluşumu hızlanır. Bu reaksiyonlar neticesinde gelişen mitokondrial oksidatif fosforilasyonun bozulması sonucu çoklu organ yetersizliği tablosu oluşur. En sik etkilenen organlar kalp, akciğerler, karaciğer, gastrointestinal sistem ve böbreklerdir (4). Bilinen bir antidotu yoktur. Bu nedenle hastaneye geç başvuran olgularda iyi bir yoğun bakım takibi yapılsa bile özellikle mortalite oranları halen çok yüksektir (5). Alüminyum fosfit zehirlenmesi sonrasında mortalite oranları \%40-80 arasında olduğu bildirilmiştir. Kalıcı miyokardiyal işlev bozukluğu gelişen hastalarda bu oran \%77'lere kadar (\%37-100) yükselmektedir (6). Bu çalışmada, bir gıda deposunda fumigasyonun ardından, sira dışı bir hikâye ile evinde meydana gelen alüminyum fosfit zehirlenmesi sonucu ölen 13 yaşındaki olgunun otopsi bulguları ile toksikolojik ve patolojik bulguları birlikte değerlendirilerek konunun literatür eşliğinde tartışılması, oral yolla kullanımı ve inhalasyonu halinde yüksek ölüm riski taşıyan alüminyum fosfitin ülkemizde kontrolsüz satışının ve kullanımının sebep olabileceği bazı olumsuzlukların vurgulanması amaçlanmıştır.

\section{Olgu}

Dosya içeriğinde; evinde fenalaşan 13 yaşındaki kız olgunun; mutfaktaki ocağın açık kalması sonucu yayılan gazdan zehirlendiği şüphesiyle hastaneye getirildiğinde kalp tepe atımı ve solunumunun olmadığı, resusite edildiği, hastanede yapılan ilk incelemelere göre olgunun kanında karbonmonoksite rastlanmadığı, aynı günlerde ailenin ikamet ettiği evin alt katındaki depoda haşerelere karşı fumigasyon işleminin yapıldığı, depodaki zehirli gazın, havalandırma boşluğundan ailenin bulunduğu eve sızdığı iddiaları üzerine kesin ölüm nedeninin tespiti için cesedin otopsisinin yapılması kararının alındığı, olay yeri inceleme ekibinin evde ve işyerinde yapmış olduğu incelemede evin mutfağında bulunan çeşitli yemeklerde alınan numuneler ile işyerinde fumigasyon için kullanılan "Phostoxin" tabletin toksikolojik açıdan incelenmek üzere XXX gönderildiği kayıtlıdır.

Düzenlenen otopsi raporunda; dış muayenede açık kırmızı renkte ölü lekelerinin ve resusitasyon müdahale- si bulgularının saptandığı, iç muayenede ise genel olarak mukozal ve serozal yapılar ile iç organ yüzeylerinde peteşial tarzda kanamalar, akciğer ağırlıklarında artış, parankiminde kanama, mide mukozasında hiperemi, mide içerisinde $50 \mathrm{cc}$ koyu renkte sıvı, bağırsaklarda, timusta hiperemi, karaciğerde normalden soluk görünüm saptandığı, histopatolojik inceleme raporlarında; intermüsküler taze kanama alanları izlenen konjesyone kalp kası, intraalveoler taze kanama alanları ve fokal ödem izlenen konjesyone akciğer, intraparankimal, intraseptal ve çevre yağlı dokuda yaygın taze kanama ile kistik dilatasyonlar içeren hassal korpuskülleri izlenen timus, hafif kronik yüzeyel gastrit izlenen mide, mukozada hafif kronik iltihabi hücre infiltrasyonu ile lenfoid hiperplazi izlenen ince barsak tespit edildiği kayıtlıdır.

Yapılan toksikolojik analizlerde; kan, organ ve midede tespit edilen fosfin gazının (PH) Perkin Elmer Clarus 580 GC TMHS 40(40TMHS) model HS/GC cihazı ile analiz edildiği, Perkin Elmer Nexion 300 D ICP-MS cihazında yapılan alüminyum tayininde; kanda $221 \mathrm{ng} / \mathrm{ml}$, organda $2907 \mathrm{ng} / \mathrm{g}$, mide içeriğinde $845 \mathrm{ng} / \mathrm{g}$ alüminyum tespit edildiği; organda tespit edilen trifenilfosfin oksitin Shımadzu GC/MS-QP 2010 Ultra cihazını ile analiz edildiği; alkol, karbonmonoksit, uyutucu ve uyuşturucu madde saptanmadığ 1 raporlarda kayıtlıdır. Ayrıca ilgili başsavcılık tarafından toksikoloji laboratuvarında incelenmek üzere gönderilen yemek numunelerinde alüminyum ve magnezyum tespit edildiği, Phostoxin tabletin analizinde ise alüminyum fosfit tespit edildiği raporlarda kayıtlıdır.

\section{Tartışma ve Sonuç}

Difüzyon kapasitesinin çok yüksek olması nedeniyle oldukça zehirli bir gaz olan fosfin gazı, uygulandığı ortamdaki istenmeyen tüm canlıları farklı gelişim evrelerinde tarım ürünlerinde kalıntı bırakmadan öldürebilmektir. Ülkemizde alüminyum fosfit tabletleri kile emdirilmiş halde sıkça kullanılmaktadır (7). Atmosferdeki nemle ya da midedeki hidroklorik asitle alüminyum fosfit tabletleri reaksiyona girdiğinde ölümcül fosfin gazı oluşmaktadır $(8,9)$. Bu özelliği nedeniyle kimyasal terörizm amaçlı kullanım riski de vardır (8). Doğal formunda renksiz ve kokusuz olan fosfin gazının ticari olarak kullanılan formlarında bazı kimyasalların ilavesi ile çürümüş balık ya da sarımsak kokusu mevcuttur (10). 1980'li yıllardan itibaren alüminyum fosfit ile zehirlenme olgularının bildirilmeye başlaması ile günümüzde birçok ülkenin tarımsal topluluklarında özkıyım amaçlı kullanımına en sık rastlanılan ajan haline gelmiştir $(8,11,12)$. Alüminyum fosfit 0,15-0,5 gram üzerindeki alımlarda mortalite ve morbiditenin oldukça yüksek olduğuna dair yayınlar mevcut 
olmasına rağmen, literatürde kesin bir toksik doz belirtilmemektedir (6,8-10). Literatürlerde fosfin zehirlenmesinin genellikle intihar ve kaza sonucu ölüme neden olduğu bildirilmiștir(13-17). Bu tip kimyasallar hastanelerdeki rutin ve standart acil laboratuvar tetkikleri listesinde yer almadığından non-spesifik bulgularla seyreden benzeri zehirlenme durumlarında doğru tanı ve tedavi için klinik şüphe ve iyi bir anamnezin yanında olay yeri inceleme bulguları ile bu bilgilerin sağlık kurumuna hızlı ve doğru bir biçimde iletilmesinin çok önemli bir destekleyici rolü olduğu düşüncesindeyiz.

Özellikle Hindistan, İran, Srilanka ve Fas'dan alüminyum fosfit zehirlenmesine bağlı ölümlerin sıklıkla görüldüğü bildirilmiştir (8). Hindistan'da yapılan bir çalışmada 559 zehirlenme olgusunun \%67,8'inin alüminyum fosfit kaynaklı olduğu saptanmıştır (18). Fas'da yapılan 10 yıllık bir çalışmada alüminyum fosfitten zehirlenen 28 olgudan 17 (\%60.7) olgunun öldüğü bildirilmiştir (19). Murali ve ark. Kuzey Batı Hindistan'da bulunan bir hastane yapmış oldukları 10 yıllık çalışmada zehirlenme nedeniyle başvuran 2884 hastanın \%26.1 alüminyum fosfit kaynaklı olduğu bildirilmiştir (20). Etemadi-Aleagha ve ark. tarafindan 2006-2013 yılları arasında Tahran'da yapılan çalışmada alüminyum fosfit zehirlenmesi sonucu ölen 2007 olgunun \%84.7'sinde $(n=1701)$ fosfin tespit edildiği bildirilmiştir (10).

Ülkemizde nadir de olsa alüminyum fosfit zehirlenmesi görülmektedir. Ekinci ve ark. yapmış oldukları çalışmada 18 yaşında kız olgunun özkıyım amaçlı alüminyum fosfit tablet alımı ile gelişen miyokard işlev bozukluğu, çoğul organ yetersizliği ve tedaviye dirençli ölümcül kardiyak aritmi nedeniyle öldüğü, yine aynı çalışmada kazara alüminyum fosfit alan 2 yaşındaki kız olgunun uygulanan tedaviye cevap vermesi sonuncunda taburcu edildiği bildirilmiştir (21). Tolunay ve ark. yapmış oldukları çalışmada 14 yaşında kız olgunun özkıyım amaçlı alüminyum fosfit içeren Celphos tablet alımı sonrasında hastaneye kaldırıldığı uygulana tedavi sonrasında hastanın taburcu edildiği bildirilmektedir (22). Hakimoğlu ve ark. yapmış oldukları çalışmada özkıyım amaçlı alüminyum fosfit tablet alımı sonrasında hastaneye getirilen 17 yaşındaki erkek olguya uygulanan tedavi sonrasında iyileşme gözlendiği bildirilmiștir (23). Demir ve ark. yapmıș oldukları çalışmada 20 yaşında erkek olgunun özkıyım amaçlı alüminyum fosfit tablet alımı sonrasında öldüğü, otopside elde edilen makroskopik ve mikroskobik bulguların nonspesifik olduğu, toksikolojik analiz sonuçlarında midede 14184 ng/g alüminyum bulunduğu, iç organ ve kas örneklerinde p-tolüen sülfonik asit saptandığ 1 bildirilmiştir (24). Olgumuzdaki fosfin zehirlenmesi oldukça sıra dışıdır. Fosfin zehirlenmesine dair herhangi bir şüphe, öykü ve spesifik bulgu olmadığından olgunun tanısı hastanede konulamamıştır. Yapılan otopsi sonrasın da dış ve iç muayene de spesifik bir bulguya rastlanmadığı, toksikolojik analizlerde kanda $221 \mathrm{ng} / \mathrm{ml}$, iç organlarda $2907 \mathrm{ng} / \mathrm{g}$ ve mide içeriğinde $845 \mathrm{ng} / \mathrm{g}$ alüminyum, kan, organ ve mide içeriğinde fosfin gazı (PH3) ve iç organlarda trifenilfosfin oksit tespit edildiği kayıtlıdır.

Sonuç olarak, doğrudan satışla, internet üzerinden ya da telefonla sipariş verilerek rahatlıkla temin edilebilmesine ve zaman zaman zehirlenmelere sebep olabilmesine rağmen, alüminyum fosfit zehirlenmeleri ülkemizde yaygın ve ciddi bir sağlık sorunu haline gelmemiştir. Çalışmamıza konu olan olgu, oturduğu apartman dairesinin alt katındaki gıda deposunda gerekli tedbirlerin alınmadan yapıldığı düşünülen bir fumigasyon işlemi sonrasında üst kata sızan fosfin gazından zehirlenmiş ve hastanede yaşamını yitirmiştir. Rutin işlemler arasında yer almadığından acil müdahale anında saptanması zor olan toksik etkisi yüksek bu tür maddelerin satışlarının kontrol altına alınabilmesi için; bu tip maddeleri satan ve fumigasyon işlemlerini uygulayanlara zorunlu bir eğitim sonrasında yetkilendirme yapılması gerektiği kanaatindeyiz. Böylece yeterli eğitim ve gerekli tedbirlerin alınmasıyla insan ölümlerinin engellenmesi yönünde bu konu üzerinden bir adım daha atılmasının diğer benzer koruyucu adımlara emsal oluşturması yönünde bilinç geliştireceğine inanıyoruz.

\section{Kaynaklar}

1. German JR, Rössel PR. Poisoning with aluminum phosphide can be life-threatening for patients as well as health professionals. Ugeskr Laeger. 2013;175:1706-7.

2. Siwach SB, Gupta A. The profile of acute poisonings in Harayana Rohtak Study. J Assoc Physicians India. 1995;43:756-9.

3. Mehrpour O, Singh S. Rice tablet poisoning: a major concern in Iranian population. Hum Exp Toxicol. 2010;29:701-2.

4. Chugh SN, Arora V, Sharma A, Chugh K. Free radical scavengers $\&$ lipid peroxidation in acute aluminium phosphide poisoning. Indian J Med Res. 1996;104:190-3.

5. Solgi R, Abdollahi M. Proposing an antidote for poisonous phosphine in view of mitochondrial electrochemistry facts. J Med Hypotheses Ideas. 2012;6:32-4.

6. Bogle RG, Theron P, Brooks P, Dargan PI, Redhead J. Aluminium phosphide poisoning. Emerg Med J. 2006;23:1. doi: 10.1136/emj.2004.015941

7. Orkun Tolunay, Tamer Çelik, Gülperi Yücel, Ulaş Özdemir, Anıl Atmış, Asena Sucu, Ümit Çelik. Nadir ama Ölümcül Olabilen Bir Zehirlenme: Alüminyum Fosfit Zehirlenmesi. J Pediatr Emerg Intensive Care Med 2017;4:27-9

8. Gurjar M, Baronia AK, Azim A, Sharma K. Managing aluminum phosphide poisonings. J Emerg Trauma Shock. 2011;4:378-84. 
9. Mehrpour O, Jafarzadeh M, Abdollahi M. A systematic review of aluminium phosphide poisoning. Arh Hig Rada Toksikol. 2012;63:61-73.

10. Etemadi-Aleagha A, Akhgari M, Iravani FS. Aluminum Phosphide Poisoning-Related Deaths in Tehran, Iran, 2006 to 2013. Medicine (Baltimore). 2015;94:1637.

11. Chaudry D, Rai AS. N-acetyl cysteine in aluminum phosphide poisoning: Myth or hope. Indian J Crit Care Med. 2014;18:646-7.

12. Chacko J, Shivaprasad C. Fatal aluminium phosphide poisoning due to myocardial depression refractory to high dose inotropic support and intra-aortic balloon counterpulsation. Indian J Crit Care Med. 2008;12:37-8.

13. Shadnia S, Mehrpour O, Abdollahi M. Unintentional poisoning by phosphine released from aluminum phosphide. Human Exper Toxicol 2008;27:87-89.

14. Musshoff F, Preuss J, Lignitz E, Madea B. A gas chromatographic analysis of phosphine in biological material in a case of suicide. Forensic Sci Int. 2008;177:35-38.

15. Shields LBE, Hunsaker DM, Hunsaker Iii JC, Ward MK. Toxicologic findings in suicide: a 10-year retrospective review of Kentucky medical examiner cases. Am J Forensic Med Pathol. 2006;27:106-112.

16. Soltaninejad K, Nelson LS, Bahreini SA, Shadnia S. Fatal aluminum phosphide poisoning in Tehran-Iran from 2007 to 2010. Indian J Med Sci. 2012;66:66-70.

17. Dias D, Mendonc, a MC, Real FC, Vieira DN, Teixeira HM. Suicides in the Centre of Portugal: seven years analysis. Fo- rensic Sci Int. 2014;234:22-28.

18. Siwach SB, Gupta A. The profile of acute poisonings in Harayana Rohtak Study. J Assoc Physicians India. 1995;43:756-9.

19. Hajouji-Idrissi M, Oualili L, Abidi K, et al. Severity factors of aluminium phosphide poisoning (Phostoxin). Ann Fr Anesth Reanim. 2006;25:382-385.

20. Murali R, Bhalla A, Singh D, et al. Acute pesticide poisoning: 15 years experience of a large North-West Indian hospital. Clin Toxicol (Phila). 2009;47:35-38.

21. Ekinci F, Yıldızdaş RD, Horoz ÖÖ, Tolu Kendir Ö 3, Petmezci E, Tolunay İ, Y1lmaz HL. Aluminium Phosphide Poisoning: Two Pediatric Patients and Two Different Clinical Outcomes. J Pediatr Emerg Intensive Care Med 2017;4:7276.

22. Tolunay O, Çelik T, Yücel G, Özdemir U, Atmış A, Sucu A, Çelik Ü. A Rare but Potentially Fatal Poisoning; Aluminum Phosphide Poisoning. J Pediatr Emerg Intensive Care Med 2017;4:27-29.

23. Hakimoğlu S, Dikey İ, Sarı A, Kekeç L, Tuzcu K, Karcıŏlu M. Successful Management of Aluminium Phosphide Poisoning Resulting in Cardiac Arrest. Turk J Anaesth Reanim 2015; 43: 288-90.

24. Demir U, Hekimoğlu Y, Aşırdizer M, Etli Y, Kartal E, Gümüş $\mathrm{O}$. A case who died due to the suicidal intake of aluminum phosphide. Cumhuriyet Medical Journal 2017;39:458465. 